\title{
EFFEKTIVITAS KOMPRES DINGIN TERHADAP SKALA NYERI DISMENOREA REMAJA PUTRI DI SMAN 2 NGAGLIK SLEMAN YOGYAKARTA
}

\author{
Melania Wahyuningsih ${ }^{1)}$ \\ ${ }^{1)}$ Fakultas Kesehatan, Universitas Respati Yogyakarta \\ Email: melania@respati.ac.id
}

Diterima: September 2021, Diterbitkan: Desember 2021

\begin{abstract}
Abstrak
Dismenorea disebabkan oleh ketidakseimbangan hormon progesterone darah yang mengakibatkan timbulnya nyeri saat menstuasi. Dismenorea bisa mengganggu aktivitas remaja putri. Cara menurunkan skala nyeri dismenorea yang murah dan efektif dengan kompres dingin. Penelitian ini merupakan quasi eksperimen pre dan post design untuk mengetahui efektivitas kompres dingin terhadap skala dismenorea. Intervensi yang diberikan melakukan kompres dingin dengan air dingin 10-15 derajat Celcius selama 15 menit. Sampel penelitian 20 remaja putri yang mengalami menstruasi hari pertama. Teknik sampling yang digunakan quota sampling. Analisa data mengunakan Wilcoxcon test. Hasil penelitian median skala dismenorea sebelum kompres dingin dan sesudah kompres dingin. Wilcoxon tes $p$ value 0,001. Kompres dingin efektif untuk menurunkan skala dismenorea remaja putri di SMAN 2 Ngaglik Sleman Yogyakarta.

Kata kunci: Dismenorea, Kompres Dingin.
\end{abstract}

\begin{abstract}
Dysmenorrhea is caused by an imbalance of the blood hormone progesterone which causes pain during menstruation. Dysmenorrhea can interfere the activities of young women. How to reduce the pain scale of dysmenorrhea that is cheap and effective with cold compresses. This study was a quasi-experimental pre and post design, to determine the effectiveness of cold compresses on the dysmenorrhoea scale. The intervention given was doing a cold compress of ice water 10-15 degrees Celsius for 15 minutes. The research sample is 20 young women who experience menstruation on the first day. The sampling technique used is quota sampling. Data analysis using Wilcoxcon test. The results of the median study on the dysmenorrhoea scale before cold compresses, and after cold compresses 5. Wilcoxon test p value 0.001. Cold compresses are effective for reducing the scale of dysmenorrhea in adolescent girls at SMAN 2 Ngaglik Sleman Yogyakarta.
\end{abstract}

Keywords: dysmenorrhea, cold compress

\section{PENDAHULUAN}

Dismenore merupakan salah satu masalah ginekologi yang paling umum dialami saat masa remaja, sangat mengganggu aktivitas bahkan seringkali mengharuskan penderita beristirahat dan meninggalkan aktivitasnya ( Fauziah, 2015). Nyeri haid / dismenore adalah keluhan ginekologis akibat ketidakseimbangan hormon progesteron dalam darah sehingga 
mengakibatkan timbul rasa nyeri yang paling sering terjadi pada wanita.

Angka kejadian dismenorea di dunia sangat besar. Lebih dari 50\% perempuan di setiap negara mengalami nyeri menstruasi. Di Amerika persentase dismenorea sekitar $60 \%$ dan di Swedia sekitar $72 \%$, sementara di Indonesia diperkirakan 55\% perempuan usia produktif yang tersiksa oleh nyeri selama menstruasi. Prevalnsi nyeri menstruasi berkisar $45-95 \%$ di kalangan wanita usia produktif (Iip, 2018). Indonesia rata-rata kejadian dismenore mencapai hingga lebih dari 50\% pada remaja putri. Data pada tahun 2014 di Daerah Istimewa Yogyakarta terdapat sebanyak 55\% remaja berusia $15-18$ tahun mengalami dismenore pada saat menstruasi, dan gangguan tersebut tidak sama antara remaja satu dengan lainnya (Dwihestie, 2018).

Empat puluh hingga tujuh puluh persen pada masa reproduksi mengalami dismenorea, dan sebesar 10 persen mengalami hingga mengganggu aktivitas sehari-hari. Sekitar 70-90 persen kasus nyeri haid terjadi saat usia remaja dan remaja yang mengalami nyeri haid akan terpengaruh aktivitas akademis, sosial dan olahraganya ( Lestari, 2013).

Wanita yang mengalami dismenore memproduksi prostaglandin 10 kali lebih banyak dari wanita yang tidak dismenore. Nyeri saat haid menyebabkan ketidaknyamanan dalam aktivitas fisik sehari - hari, dan ketidakhadiran berulang di sekolah ataupun di tempat kerja, sehingga dapat mengganggu produktivitas. Remaja putri lebih sering merasakan sakit akibat disemorea primer karena siklus hormonal yang belum begitu stabil.

Upaya untuk mengurangi keluhan pada dismenorea primer, dapat dilakukan dengan penggunaan kompres dingin, mengkonsumsi obat-obatan analgetik, olahraga teratur, akupuntur, dan mengkonsumsi produk-produk herbal/jamu yang telah dipercaya khasiatnya. Pemberian obat analgetik pada dismenorea misalnya aspirin dan asetaminofen, diuretik misalnya tiazida, spasmolitik, dan pengobatan suportif yang meliputi aktifivas fisik misalnya olahraga senam dan yoga. Cara lainnya untuk mengatasi dismenorea adalah dengan tidur yang cukup, diet, dan fisioterapi. Penggunaan obat-obatan analgesik seperti aspirin dapat menimbulkan efek samping seperti iritasi mukosa lambung, dan meningkatkan resiko tukak lambung, dan meningkatkan resiko perdarahan, sedangkan asetaminofen dapat menyebabkan efek samping seperti hipersensitifitas, kerusakan hati, mual, muntah, dan anoreksia ( Wulandari, 2018).

Cara non farmakologik merupakan cara mengatasi dismenorea tanpa efek samaping.Cara untuk mengatasi dismenoreadengan tanpa efek samping dapat dilakukan dengan kompres. Kompres dibagi menjadi dua yaitu kompres hangat dan dan kompres dingin. Kompres dingin dapat diletakan pada daerah yang terasa nyeri biasanya pada bagian pinggang, perut bagian bawah atau lipatan paha ketika ada kontraksi dengan menggunakan buli-buli dingin yang diisi dengan air dingin dengan suhu $15-18^{\circ} \mathrm{C}$ selama 5-10 menit (Seingo, 2018).

Tujuan diberikan kompres dingin adalah menghilangkan rasa nyeri akibat trauma atau odema, mencegah kongesti kepala, memperlambat denyut jantung, mempersempit pembuluh darah dan mengurangi aliran darah lokal. Kompres dingin menstimulasi kulit sehingga meningkatkan pelepasan endorfin yang memblok transmisi stimulasi nyeri dan juga menstimulasi serabut saraf berdiameter besar A-Beta sehingga menurunkan transmisi implus nyeri melalui serabut kecil A-delta dan serabut saraf C (Irawan, 2018) 


\section{METODE PENELITIAN}

Penelitian ini merupakan penelitian quasi eksperimen dengan pre dan post test desain tanpa kontrol group. Sampel penelitiann terdiri dari 20 remaja putri yang mengalami dismenorea di SMA N2 kelas XI Ngaglik Sleman Yogyakarta. Kelompok intervensi dan kelompok kontrol semuanya remaja putri yang sudah mengalami menstruasi sebelumnya. Teknik sampling menggunakan kuota sampling. Intervensi yang diberikan adalah kompres dingin dengin air es dengan suhu 10 - 15 derajat Celcius yang diletakkan pada abdomen bagian bawah dengn menggunakan buli - buli air dingin selama 15 menit pada hari pertama dismenorea. Pengukuran skala nyeri dismenorea dilakukan langsung setelah dilakukan kompres dingin. Sebelum data penelitian diambil penelitu menyebarkan kuesioner untuk mengidentifikasi remaja putri yang mengalami dismenorea dan perkiraan tanggal menstruasi. Pada perkiraan waktu menstruasi peneliti menghubungi responden. Pengambilan data penelitian dilaksanakan pada 11 Maret - 12 April 2019 saat jam istirahat di uang UKS dengan didampingi guru BP. Skala nyeri diukur sebelum dan sesudah pemberian kompres dingin dengan menggunakan skala Numeric Rating Scale (NRS). Analisa data menggunakan uji Wilcoxon.

\section{HASIL DAN PEMBAHASAN}

Tabel 1: Perbedaan Skala dismenorea sebelum dan sesudah kompres dingin pada remaja putri di SMA N2 Kelas XI Ngaglik Sleman Yogyakarta.

\begin{tabular}{lllllll}
\hline Skala dismenorea & Median & $\begin{array}{l}\text { Beda } \\
\text { Median }\end{array}$ & Nilai Min & Nilai Max & SD & P value \\
\hline Pre Test & 6 & 1 & 4 & 8 & 1.57 & 0.001 \\
Post Test & 5 & & 1 & 8 & 1.84 & \\
\hline
\end{tabular}

Sumber: Data primer 2019

Pada penelitian ini tidak menampilkan karakteristik responden karena semua respondennya remaja putri kelompok emaja akhir antara 17 - 19 tahun.

Dismenorea adalah nyeri yang timbul pada saat wanita mengalami menstruasi, disebabkan karena kontraksi otot moimetrium yang berlebihan maka akan mengurangi aliran darah, sehingga kekurangan oksigen dalam sel-sel miometrium yang mengakibatkan timbulnya nyeri pada saat menstruasi spasmodik, nyeri ini menyebabkan perut terasa mulas. Ini terjadi pada semua wanita yang mengalami menstruasi (Lowdermilk, dkk :2013).

Dari tabel 1 skala dismenorea remaja putri sebelum diberikan terapi kompres dingin 6 , nilai minimum 4 dan nilai maximum 8 dengan standar deviasi 1.57.
Sesudah diberikan terapi kompres dingin skala dismenorea remaja putri turun menjadi 5 , nilai minimum 1 , nilai maximum 8 dengan standar deviasi 1.84. Skala dismenorea sebelum diberikan kompres dengan median pada skala 6 pada rentang nyeri sedang, sedangkan setelah diberikan terapi kompres dingin skala dismenorea pada skala 5, dalam rentang nyeri sedang. Meskipun sebelum dan sesudah kompres dingin tetap dalam rentang nyeri sedang, ada perbedaan nilai median 1, sebelum dan sesudah kompres dingin, yang berarti kompres dingin bias menurunkan skala dismenorea. Hal ini dibuktikan dari analisa Wilcoxon dengan $\mathrm{p}$ value 0.001 ( $\mathrm{p}$ value $<0.05$ ), ada perbedaan yang significant skala dismenorea sebelum dan sesudah diberikan kompres dingin pada remaja putri di SMAN 2 Ngaglik Sleman Yogyakarta. 
Ketidaknyamanan dismenorea yang dirasakan oleh remaja putri mengeluh kram, mules, perut kembung dan tidak nyaman pada perut bagian bawah, sehingga mengganggu dalam beraktivitas. Remaja putri mengatakan tidak bisa beraktivitas seperti biasa karena tidak nyaman pada perut. Ketidaknyamanan ini berlangsung pada hari pertama dan kedua. Upaya untuk mengurangi rasa idak nyaman yang dilakukan antara lain dengan mengolesi minyak kayu putih pada abdomen.

Pada penelitian kompres dingin menggunnakan air es dengan suhu 10-15 derajat yang dimasukkan ke dalam buli - buli air dingin, diletakkan pada daerah nyer, yaitu pada abdomen bagaian bawah selama 15 menit. Posisi saat dilakukan kompres dingin duduk rileks atau berbaring di ruang UKS. Istirahat dari aktivitas dan rileks memberikan rasa tenang dan nyaman. Sensasi dingin yang dialirkan dari buli buli air ke permukaan kulit abdomen bagian bawah memberikan rasa nyaman sehingga menurunkan skala nyeri. Kompres es mengakibatkan vaso konstriksi pembuluh darah disekitar daerah yang dikompres, sehingga aliran darah ke daerah tersebut berkurang, selanjutnya amengurangi rasa kram di abdomen dan nyaman, dan nyeri berkurang. Hal ini ditunjukkan dengan skala nyeri sebelum diberikan kompres dingin nilai median 6 dan sesudah diberikan kompres dingin dengan nilai median 5. Penurunan nilai median 1 angka ini menunjukkan bahwa dengan kompres dingin skala nyeri dismenorea pada pada remaja putri di SMA Negeri 2 Ngaglik.

Pada penelitian ini waktu munculnya dismenorea muncul pada hari pertama dan kedua sejak mulai menstruasi, hal ini sesuai dengan penelitian Novia (2008). Waktu munculnya gejala dismenore primer responden yaitu 56,3\% muncul $<12$ jam sejak mulaisejak mulai menstruasi, 42,3\% muncul 12-24 jam sejak mulai, 42,3\% muncul 12-24 jam sejak mulai mulai menstruasi dan sisanya $1,4 \%$ muncul $>24$ jam sejak dan sisanya $1,4 \%$ muncul $>24$ jam sejaksejak mulai menstruasi. Mayoritas waktu munculnya gejala. Mayoritas waktu munculnya gejala dismenore primer berbeda untuk setiap wanita. Dari hasil tabel di atas menunjukkan bahwa sebagian besar waktu munculnya gejala dismenore primer $<24$ jam $(96,8 \%)$. Hal ini biasanya terjadi sebelum dan bersamaan dengan mulainya menstruasi dan ada pula yang berlangsung untuk menstruasi dan ada pula yang berlangsung untuk beberapa hari selama menstruasi.

Pada penelitian ini remaja putri tidak mengetahui penyebab dismenorea, karena sejak pertama menstruasi sering mengalami kram dan ketidak nyamanan pada perut bagian bawah. Penyebab pasti dismenorhea sampai saat ini belum jelas, dahulu disebutkan karena faktor keturunan, psikis, dan lingkungan dapat mempengaruhi terjadinya dismenorhea, namum penelitian terakhir menunjukkan adanya pengaruh suatu zat kimia dalam tubuh yang disebut prostaglandin (PG). Pada keadaan tertentu dimana kadar prostaglandin berlebihan maka kontraksi uterus (rahim) akan ikut bertambah sehingga menyebabkan nyeriyang hebat (Anurogo, 2008).

Kompres dingin dingin dapat menurunkan skala dismenorea karena kompres dingin berfungsi mengurangi peradangan dengan cara mengerutkan atau mengecilkan pembuluh darah. Meskipun kompres dingin akan menimbulkan rasa tidak nyaman di awal, tetapi cara ini bisa meredam rasa nyeri seperti yang lakukan dalam penelitian oleh Phona (2014).

Pada penelitian ini sebelum dilakukan kompres dingin selama 15 menit didapatkan hasil bahwa rmedian skala disminorea yaitu 6 dengan standar deviasi 1,57, sedangkan nilai median skala dismenorea setealh dilakukan kompres dingin 5 dengan standar deviasi 1,81. Penelitian ini sejalan dengan penelitian yang dilakukan oleh Murtiningsih 
dan Karlina, pada penelitian tersebut didapatkan hasil bahwa rata-rata skala disminorea sebelum dilakukan kompres hangat yaitu 6,50 dan setelah dilakukan kompres hangat yaitu 4,22 ( Murtiningsih< 2015)

Hasil analisa Wilcoxon skala dismenorea sebelum dan sesudah kompres es diperoleh $\mathrm{p}$ value 0,001 ( $\mathrm{P}$ value $<0,05$ ) yang artinya kompres dingin efektif untuk menurunkan skala dismenorea pada remaja putri di SMA N2 Kelas XI Ngaglik Sleman Yogyakarta. Kompres dingin yang diberikan dengan air dingin $10-15$ derajat menurunkan skala nyeri. Hal ini menunjukkan bahwa skala dismenorea bisa diturunkan dengan menggunakan cara non farmakologik salah satunya dengan menggnakan kompres dingin. Kompres air dingin dengan suhu 10-15 derajat bisa menurunkan aliran darah yang menuju daerah yang dikompres yaitu daerah uterus, sehingga menurunkan kadar prostaglandin yang berada dalam aliran darah sehingga bisa mengurangi spasme pada abdomen. Yang dilamai oleh responden nyaman dan saat diukur skala dimenoreanya turun .

Hasil penelitian ini menunjukan bahwa setelah dilakukan kompres dingin pada siswi SMA N 2 Ngaglik yang mengalami disminorea terbukti bahwa kompres hangat dapat menurunkan skala disminorea. Responden menyatakan skala disminorea yang dirasakan menurun setelah dilakuakan kompres dingin. Dari hasil tersebut dapat disimpulkan bahwa kompres dingin berpengaruh terhadap penuruanan skala disminorea pada remaja.

Penelitian ini sejalan dengan penelitian (Irawan, 2018) dengan judul penelitian Perbandingan tekhnik relaksasi nafas dalam dan kompres dingin terhadap penurunan tingkat nyeri haid (dismenore) pada mahasiswi di asrama Sanggau dan ikatan keluarga Belu di Landungsari Kota Malang. Hasil penelitian menunjukkan bahwa kompres dingin lebih efektif menurunkan tingkat nyeri haid dengan $\mathrm{t}$ value $(18,380)$ daripada tekhnik relaksasi nafas dalam yang hanya mengalami penurunan sebesar 6,263 dengan p-value tekhnik relaksasi nafas dalam $(0,000)<$ $(0,050)$ dan $\mathrm{p}$-value kompres dingin $(0,000)$ $<(0,050)$. Yang berbeda pada penelitian ini pada responden penelitianya. Responden pada penelitian ini remaja putri di SMA sedangkan Irawan pada mahasiswi.

Penelitian ini sejalan dengan penelitian (Rahmadaniah, 2018) Hasil penelitian ini menggunakan uji chi square diperoleh nilai signifikan $0,048 \quad(\mathrm{p}<$ 0,05)artinya terdapat perbedaan pemberian kompres hangat dan kompres dingin terhadap tingkat nyeri menstruasi.

\section{SIMPULAN}

1. Skala dismenorea remaja putri SMAN2 Ngaglik Sleman sebelum diberikan kompres dingin median 6 dan sesudah diberikan kompres dingin 5

2. Kompres dingin efektif menurunkan skala dismenorea remaja putri di SMAN2 Ngaglik Sleman

\section{DAFTAR PUSTAKA}

Dwihestie, L. K. (2018). Hubungan Usia Menarche Dan Tingkat Stres Dengan Kejadian Dismenore Primer Pada Remaja Putri. Jurnal Ilmiah Kebidanan (Scientific Journal of Midwifery), 4(2), 77-82.

Fauziah, M. N. (2015). Pengaruh Latihan Abdominal Stretching Terhadap Intensitas Nyeri Haid (Dismenore) pada Remaja Putri di SMK Al Furqon Bantarkawung Kabupaten Brebes.

Iip, J. S. S. (2018). Gambaran Derajat Nyeri Menstruasi (Dismenorea) Pada Siswi Di Sma Negeri 1 Cisarua 2018.

Irawan, F. D., Sudiwati, N. L. P. E., \& Dewi, N. (2018). Perbandingan Tekhnik Relaksasi Nafas Dalam Dan Kompres 
Dingin Terhadap Penurunan Tingkat Nyeri Haid (Dismenore) Pada Mahasiswi Di Asrama Sanggau Dan Ikatan Keluarga Belu Di Landungsari Kota Malang. Nursing News: Jurnal Ilmiah Keperawatan, 3(1).

Lestari, N. M. S. D. (2013, December). Pengaruh dismenorea pada remaja. In Prosiding Seminar Nasional MIPA.

Lubis, P. Y. (2019). Faktor-faktor yang berhubungan dengan kejadian dismenore primer pada remaja siswi Sma Dharma Sakti Medan tahun 2018.

Murtiningsih \& Karlina, L. (2015). Penurunan Nyeri Disminorea Melalui Kompres Hangat Pada Remaja. 3, 88-96.

Novia, I., \& Puspitasari, N. (2008). Faktor risiko yang mempengaruhi kejadian Dismenore Primer. The Indonesian Journal of Public Health, 4(3).

Rahmadaniah, I. (2018). Perbandingan Pemberian Kompres Hangat dan
Kompres Dingin terhadap Tingkat Nyeri Menstruasi. Cendekia Medika, 3(1), 2934.

Seingo, F., Sudiwati, N. L. P. E., \& Dewi, N. (2018). Pengaruh kompres dingin terhadap penurunan intensitas nyeri pada wanita yang mengalami dismenore di Rayon Ikabe Tlogomas. Nursing News: Jurnal Ilmiah Keperawatan, 3(1).

Suwanti, S., Wahyuningsih, M., \& Liliana, A. (2018). Pengaruh aromaterapi lemon (Cytrus) terhadap penurunan nyeri menstruasi pada mahasiswi di universitas respati yogyakarta. Jurnal Keperawatan Respati Yogyakarta, 5(1), 345-349.

Wulandari, A., Rodiani, R., \& Sari, R. D. P. (2018). Pengaruh Pemberian Ekstrak Kunyit (Curcuma longa linn) dalam Mengatasi Dismenorea. Jurnal Majority, 7(2), 193-197. 